NASA/TM-2010-216736

\title{
A Microwave Blade Tip Clearance Sensor for Propulsion Health Monitoring
}

Mark R. Woike

Glenn Research Center, Cleveland, Ohio

Ali Abdul-Aziz

Cleveland State University, Cleveland, Ohio

Timothy J. Bencic

Glenn Research Center, Cleveland, Ohio 


\section{NASA STI Program . . . in Profile}

Since its founding, NASA has been dedicated to the advancement of aeronautics and space science. The NASA Scientific and Technical Information (STI) program plays a key part in helping NASA maintain this important role.

The NASA STI Program operates under the auspices of the Agency Chief Information Officer. It collects, organizes, provides for archiving, and disseminates NASA's STI. The NASA STI program provides access to the NASA Aeronautics and Space Database and its public interface, the NASA Technical Reports Server, thus providing one of the largest collections of aeronautical and space science STI in the world. Results are published in both non-NASA channels and by NASA in the NASA STI Report Series, which includes the following report types:

- TECHNICAL PUBLICATION. Reports of completed research or a major significant phase of research that present the results of NASA programs and include extensive data or theoretical analysis. Includes compilations of significant scientific and technical data and information deemed to be of continuing reference value. NASA counterpart of peer-reviewed formal professional papers but has less stringent limitations on manuscript length and extent of graphic presentations.

- TECHNICAL MEMORANDUM. Scientific and technical findings that are preliminary or of specialized interest, e.g., quick release reports, working papers, and bibliographies that contain minimal annotation. Does not contain extensive analysis.

- CONTRACTOR REPORT. Scientific and technical findings by NASA-sponsored contractors and grantees.
- CONFERENCE PUBLICATION. Collected papers from scientific and technical conferences, symposia, seminars, or other meetings sponsored or cosponsored by NASA.

- SPECIAL PUBLICATION. Scientific, technical, or historical information from NASA programs, projects, and missions, often concerned with subjects having substantial public interest.

- TECHNICAL TRANSLATION. Englishlanguage translations of foreign scientific and technical material pertinent to NASA's mission.

Specialized services also include creating custom thesauri, building customized databases, organizing and publishing research results.

For more information about the NASA STI program, see the following:

- Access the NASA STI program home page at http://www.sti.nasa.gov

- E-mail your question via the Internet to help@ sti.nasa.gov

- Fax your question to the NASA STI Help Desk at $443-757-5803$

- Telephone the NASA STI Help Desk at 443-757-5802

- Write to: NASA Center for AeroSpace Information (CASI) 7115 Standard Drive Hanover, MD 21076-1320 
NASA/TM-2010-216736

\section{A Microwave Blade Tip Clearance Sensor for Propulsion Health Monitoring}

Mark R. Woike

Glenn Research Center, Cleveland, Ohio

Ali Abdul-Aziz

Cleveland State University, Cleveland, Ohio

Timothy J. Bencic

Glenn Research Center, Cleveland, Ohio

Prepared for the

Infotech@Aerospace 2010 Conference

sponsored by the American Institute of Aeronautics and Astronautics Atlanta, Georgia, April 20-22, 2010

National Aeronautics and

Space Administration

Glenn Research Center

Cleveland, Ohio 44135 
This report contains preliminary findings, subject to revision as analysis proceeds.

Trade names and trademarks are used in this report for identification only. Their usage does not constitute an official endorsement, either expressed or implied, by the National Aeronautics and Space Administration.

Level of Review: This material has been technically reviewed by technical management.

Available from

NASA Center for Aerospace Information 7115 Standard Drive

Hanover, MD 21076-1320
National Technical Information Service 5301 Shawnee Road Alexandria, VA 22312

Available electronically at http://gltrs.grc.nasa.gov 


\title{
A Microwave Blade Tip Clearance Sensor for Propulsion Health Monitoring
}

\author{
Mark R. Woike \\ National Aeronautics and Space Administration \\ Glenn Research Center \\ Cleveland, Ohio 44135 \\ Ali Abdul-Aziz \\ Cleveland State University \\ Cleveland, Ohio 44115 \\ Timothy J. Bencic \\ National Aeronautics and Space Administration \\ Glenn Research Center \\ Cleveland, Ohio 44135
}

\begin{abstract}
Microwave sensor technology is being investigated by the NASA Glenn Research Center as a means of making non-contact structural health measurements in the hot sections of gas turbine engines. This type of sensor technology is beneficial in that it is accurate, it has the ability to operate at extremely high temperatures, and is unaffected by contaminants that are present in turbine engines. It is specifically being targeted for use in the High Pressure Turbine (HPT) and High Pressure Compressor (HPC) sections to monitor the structural health of the rotating components. It is intended to use blade tip clearance to monitor blade growth and wear and blade tip timing to monitor blade vibration and deflection. The use of microwave sensors for this application is an emerging concept. Techniques on their use and calibration needed to be developed. As a means of better understanding the issues associated with the microwave sensors, a series of experiments have been conducted to evaluate their performance for aero engine applications. This paper presents the results of these experiments.
\end{abstract}

\section{Introduction}

The development of instrumentation and sensors for the in situ health monitoring of gas turbine engines is of high interest to NASA's Aviation Safety Program (AVSP). The rotating components of modern gas turbine engines operate in severe environmental conditions and are exposed to high thermal and mechanical loads. The cumulative effects of these loads over time can lead to high stresses, structural deformity, and eventual component failure. Current risk-mitigation practices involve periodic inspections and schedule-based maintenance of engine components to ensure their integrity over the lifetime of the engine. These methods have their limitations, and failures have been experienced leading to unscheduled maintenance and unplanned engine shutdowns. To prevent these failures and enhance aviation safety, the NASA Integrated Vehicle Health Management (IVHM) Project, as part of the overall AVSP, is investigating new types of sensor technologies for the in situ structural health monitoring and detection of flaws in gas turbine engines.

The use of sensors for in situ health monitoring of gas turbine engines requires sensors that are highly accurate and can operate in a high temperature environment. Microwave sensor technology is being investigated by the NASA Glenn Research Center as a means of making non-contact structural health 
measurements in the hot sections of gas turbine engines. It is specifically being targeted for use in the HPT and HPC sections to directly monitor the structural health of the rotating components. Blade damage in the HPT and HPC sections account for $\sim 12$ percent of the in flight engine shutdown events and $\sim 32$ percent of the damage events that caused engine removal for unscheduled maintenance (Ref. 1). The capability to make in-situ health measurements is a need that has been identified by the aero IVHM community. Microwave sensor technology is appealing in that it is accurate, it has the ability to operate at extremely high temperatures, and is unaffected by contaminants that are present in turbine engines. As a means of better understanding the issues associated with the microwave sensors, a series of five experiments were conducted at the NASA Glenn Research Center to evaluate their performance on aero turbine engine like components. This paper presents the background and the theory of the microwave sensors and the results of the experimental work performed.

\section{Sensor Background and Theory}

The microwave tip clearance sensor technology used in these experiments was developed by Radatec, Inc. (now Vibro-Meter, SA) as part of NASA's Small Business Innovation Research Program (SBIR) along with other commercial contracts. The initial $5.8 \mathrm{GHz}$ microwave blade tip clearance system and several first generation probes were delivered to the NASA Glenn Research Center in 2006 to 2008 timeframe as part of a Phase III SBIR commercialization contract. A $24 \mathrm{GHz}$ microwave blade tip clearance system and several second generation probes were delivered as part of a subsequent commercial contract. The microwave tip clearance sensor system works on principles that are similar to a short range radar system. The tip clearance probe is both a transmitting and receiving antenna. The sensor emits a continuous microwave signal and measures the signal that is reflected off a rotating blade. The motion of the blade phase modulates the reflected signal. The reflected signal is then compared to an internal reference signal and the phase difference directly corresponds to the distance to the blade. More detailed information on the sensor's theory of operation can be found in References 2 to 5 .

The microwave blade tip clearance system consists of two major components. The first component is the probe (Fig. 1). The probe contains the transmitting and receiving antenna and is designed to be installed in the casing of the engine where it can measure the radial clearance between the face of the sensor and the turbine blade tips. The second component is the sensor electronics (Fig. 2). The sensor contains the RF generator, RF detector, and all of the associated hardware required to generate, measure, and convert the microwave signals into a displacement reading. The sensor electronics are designed to be located off-board of the engine in an environmentally benign area. The probes are connected to the sensor electronics using a microwave rated co-axial cable. A rack-mounted PC is used to interface to the sensor electronics and run the data acquisition and display software. The data acquisition computer is connected to the sensor electronics through a network switch. The data acquisition computer is intended to be remotely located away from the sensor electronics in an area such as a control room using a CAT5E connection.

The microwave blade tip clearance probes are made of high temperature material and our designed to operate in temperature of $900{ }^{\circ} \mathrm{C}$ uncooled, $1200{ }^{\circ} \mathrm{C}$ with cooling air. The first generation probes operate at $5.8 \mathrm{GHz}$ and can measure clearance distances up to $\sim 25 \mathrm{~mm}$ (i.e., one-half the radiating wavelength). The second generation probes operate at $24 \mathrm{GHz}$ and in theory can measure clearance distances up to $\sim 6$ $\mathrm{mm}$. In regards to physical size, the first generation $5.8 \mathrm{GHz}$ probes are approximately $14 \mathrm{~mm}$ in diameter and $26 \mathrm{~mm}$ long. The second generation $24 \mathrm{GHz}$ probes are approximately $9 \mathrm{~mm}$ in diameter and $19 \mathrm{~mm}$ long. This technology has an ultimate goal of obtaining clearance accuracies approaching $25 \mu \mathrm{m}$.

Accuracies on this order were observed in the laboratory and will be discussed in subsequent section of this paper. A frequency response of up to $5 \mathrm{MHz}$ is typical, with up to $25 \mathrm{MHz}$ being possible with this technology (Ref. 4). 


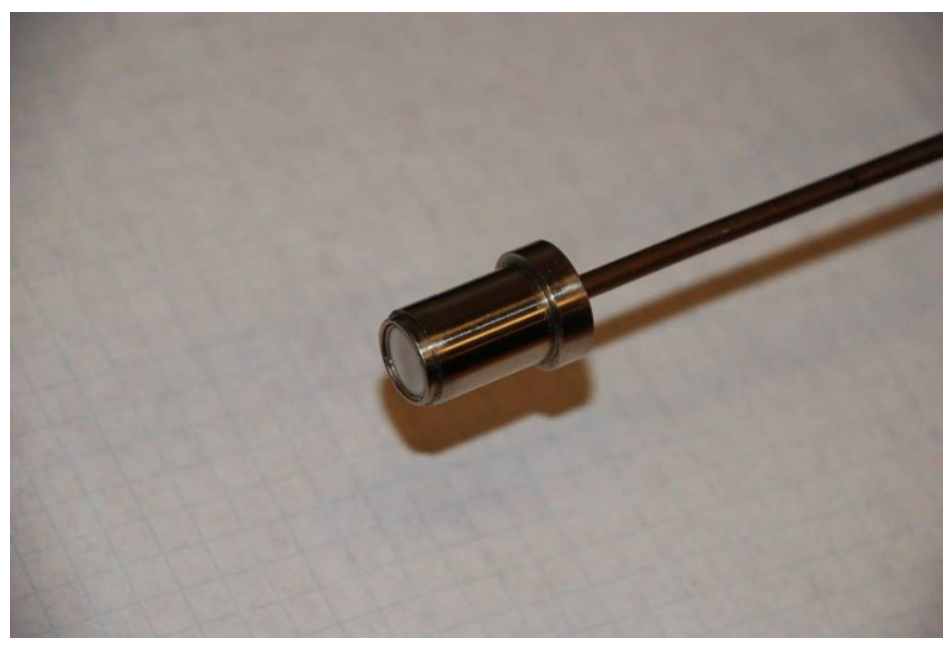

Figure 1.-Microwave blade tip clearance probe, $5.8 \mathrm{GHz}$.

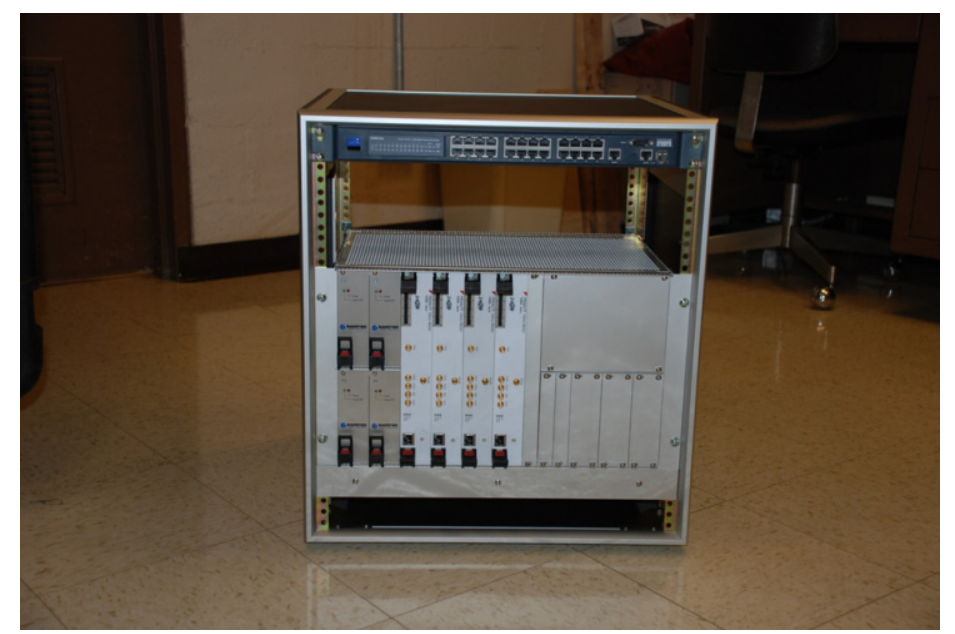

Figure 2.-Microwave sensor electronics, $24 \mathrm{GHz}$ system, $\mathrm{x} 4$ channels.

\section{Experimental Approach}

The primary goal for this technology under the NASA AVSP's IVHM Project is to demonstrate it on an actual gas turbine engine in a relevant high temperature environment. The microwave blade tip clearance probe's accuracy, high temperature capability, high frequency response, and ability to see through contaminants are major discriminators between it and other sensor technologies. There is a strong interest in using the sensors to monitor the structural health of rotating components. It is intended to use blade tip clearance to monitor blade growth and wear and blade tip timing to monitor blade vibration and deflection. Being able to get both clearance and deflection measurements from one probe presents an ideal solution to the IVHM community. However, the use of microwave sensors for this application is an emerging concept that requires further investigation. Techniques on their use and calibration are not yet fully developed. In addition, the microwave sensor's accuracy and ability to make blade tip clearance and deflection measurements had to be assessed, prior to their use on actual engine hardware.

As a means of better understanding the issues associated with the microwave sensors, a series of five experiments were conducted at the NASA Glenn Research Center to evaluate their performance on aero engine type applications. The first three experiments covered the calibration of the microwave sensors 
and their use to make clearance measurements on a large Axial Vane Fan and a subscale NASA Turbofan. These tests were conducted using the first generation, $5.8 \mathrm{GHz}$, version of the microwave sensors in order to better understand the use of microwave sensors and their accuracy. The results from these experiments have been previously reported in Reference 6 and for the purposes of this paper only a subset of the results will be presented from these experiments. The last two experiments were confined to the use of the second generation, $24 \mathrm{GHz}$, version of microwave sensors. This version of sensor is specifically targeted towards aero engine applications. The fourth experiment involved the use of a microwave sensor to make blade tip clearance and blade tip deflection measurements on a subscale simulated turbine engine disk with blades bent at pre-defined angles. This test was conducted to evaluate the second generation sensor's ability to make blade deflection measurements on turbine engine like hardware. The fifth experiment focused on the calibration of a sensor using a compressor disk from a small aero engine as the measurement target. This was done to calibrate and evaluate the second generation sensor's ability to measure blade tip clearances on actual hardware over the low clearance ranges typically associated with an aero engine. Details covering the results obtained from all five experiments are presented in the following sections.

\section{Calibration Experiment}

The first experiment that was accomplished with the microwave tip clearance system was the calibration and evaluation of the probes using a bench top calibration rig. Like other sensor technologies, measurements made with the microwave sensors are very specific to the geometry of the blade being measured. The sensor makes an average measurement of the spot size that is projected on the blade. To obtain accurate and useful results, this average or "uncorrected" measurement needs to be mapped to the actual minimum clearance between the blade and the sensor. This is done by calibrating the sensor against the blade geometry that will be used for the tip clearance measurements. Since the use of microwave sensors is an emerging technology, techniques on calibration and installation effects are not fully quantified as they are for older technologies. The main goal of this experiment was to develop the infrastructure and techniques to calibrate the probes for use on experiments at the Glenn Research Center. In addition, the calibration rig provided a good venue to evaluate the probe's accuracy and understand any effects associated with the probe's installation.

The calibration rig setup is shown in Figure 3. It consists of a rotary stage and a linear stage that is controlled by a programmable motion controller. The target geometry or blade to be calibrated against is mounted on the rotary stage where it can be operated at speeds up to $300 \mathrm{rpm}$. The microwave probe to be calibrated is mounted on the linear stage where its radial distance to the rotating target can be varied over the desired clearance range for the calibration. This linear stage has an optical encoder with an accuracy of $4 \mu \mathrm{m}$ for position indication. For the initial calibration experiment, the calibration was accomplished on two different blade geometries to understand how geometry effected the measurements. The first geometry that was tested was a relatively thin first stage compressor blade. This blade, shown in Figure 4, was $\sim 105 \mathrm{~mm}$ long, $\sim 6 \mathrm{~mm}$ thick at its widest point, and had a chord length of $\sim 37 \mathrm{~mm}$. It was chosen to see how well the probes would calibrate against a blade's geometry that was smaller than the probe's diameter. The second geometry tested was a flat box. This box, shown mounted on the rotary stage in Figure 3, was $\sim 26 \mathrm{~mm}$ thick, $\sim 76 \mathrm{~mm}$ high, and $\sim 107 \mathrm{~mm}$ long. It was chosen to simulate a blade that was thicker than the probe's diameter. In addition, it replicated the thickness of the blades of an axial vane fan that the probes were used on in a subsequent experiment. 


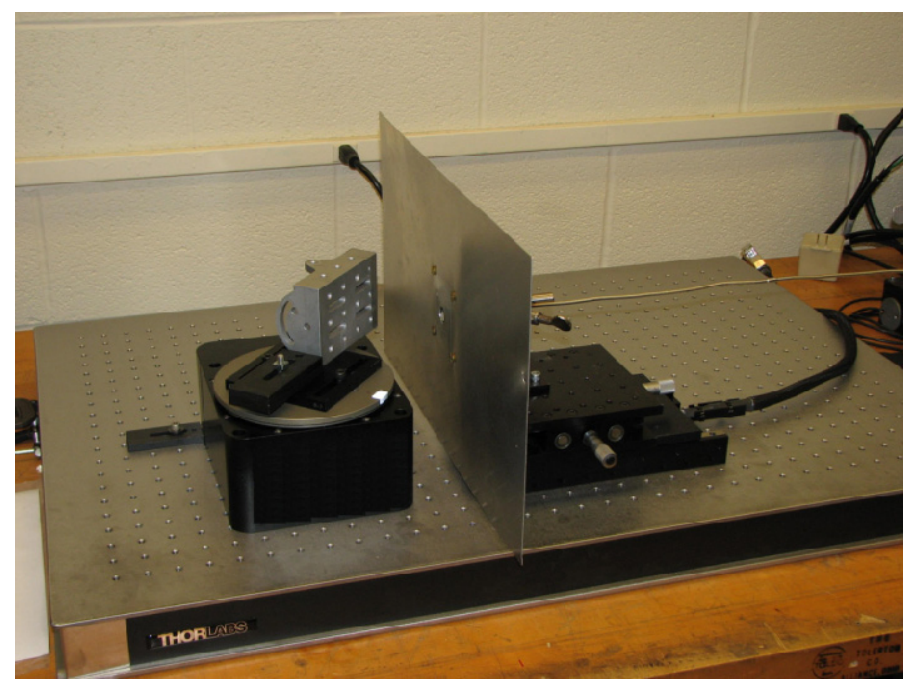

Figure 3.-Microwave probe calibration rig.

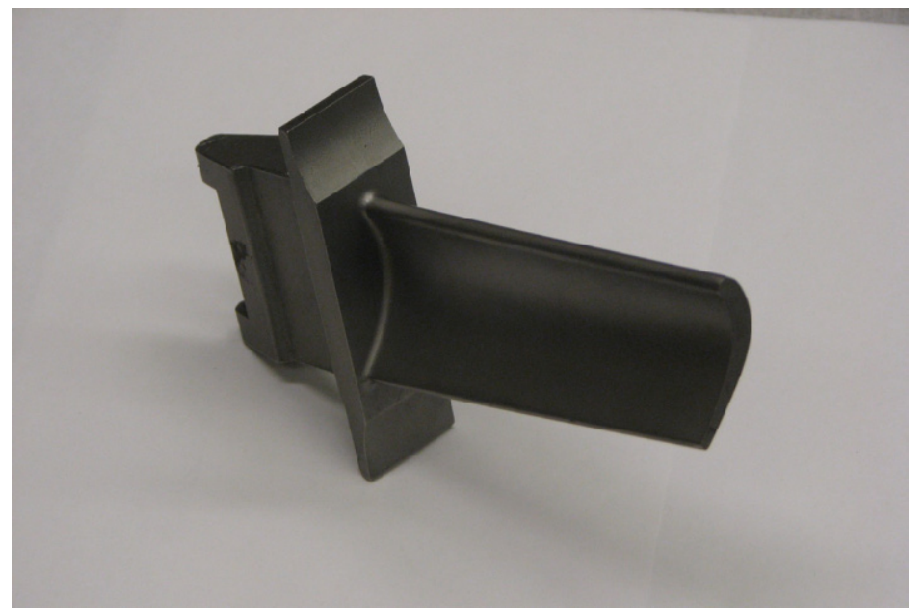

Figure 4.-Compressor blade used for calibration.

The following items need to be considered when using and calibrating the microwave sensors. First, the target needs to rotate or move in order for the sensor to measure it. This is because the system operates on the principle of extracting the phase modulation, caused by the motion of the blades, from the reflected signal. Second, the microwave probes were designed to be mounted in a metallic casing or reference plane. This allows the microwave field to emit properly from the face of the probe. The first generation probes used in this experiment were designed to be recessed by $0.50 \mathrm{~mm}$ in an engine or fan casing. A 265 by $425-\mathrm{mm}$ metal sheet was used to simulate the fan casing for the calibration experiment. In addition, the microwave field emitted from the probe has a polarity (or shape). This feature can be used as an extra adjustment in improving the quality of the signal based on the size of blades and overall geometry. To maximize the amount of signal that is sent out and collected from a blade, the face of the probe is aligned so its polarity is in-line or parallel with the blade tip's chord. To minimize the amount of signal that is sent out and collected from the blade the probe is rotated so its polarity is perpendicular to the blade tip's chord. Generally, it is recommended by the manufacturer that a parallel alignment be used for blades that are much thinner than the diameter of the probe and a perpendicular alignment be used for blades that are thicker than the diameter of the probe. Usually, the best response may fall somewhere inbetween. The probe alignment is a trade off that needs to be made based on the application. During this calibration experiment the probe's polarity was varied as a means of assessing and understanding this additional installation effect. 


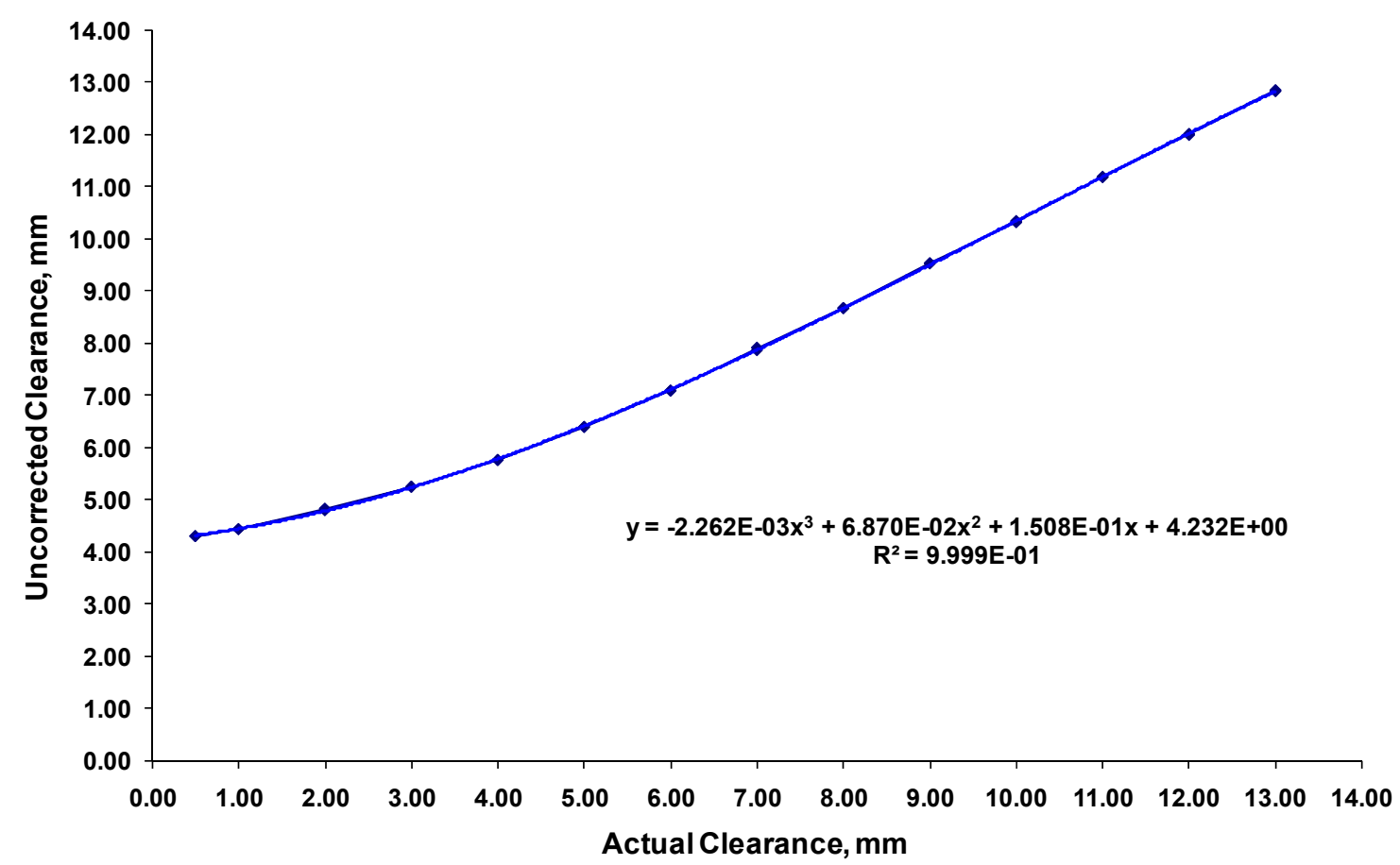

Figure 5.-Calibration curve for thin blade.

The calibration curve for a microwave probe using the thin compressor blade is shown in Figure 5. The $y$-axis is the uncorrected clearance reading that was acquired from the probe. The $\mathrm{x}$-axis is the actual clearance. It represents the distance between the simulated fan casing, with sensor, and the tip of the blade. The calibration was done over a range of 0.5 to $13.0 \mathrm{~mm}$. The resulting curve is a third-order polynomial and has fairly good sensitivity at clearances above $2 \mathrm{~mm}$. At clearances lower than $2 \mathrm{~mm}$, the response flattens out and the sensor becomes less sensitive. This effect is believed to be caused by the near field properties of the probe's antenna and its interaction with the geometry of the relatively thin blade. The curve observed in Figure 5 was a typical response when using the probes on a thin blade when compared to the probes diameter. For this calibration the sensor's polarity was aligned to be parallel with the chord of the blade to maximize the amount of energy reflected from the blade.

Figure 6 shows the calibration curve for the same probe against the simulated thick blade. This calibration was undertaken as a means of capturing the necessary correction data for measuring the tip clearances on a large axial vane located at the NASA Glenn Research Center. As in the previous case, the $\mathrm{y}$-axis is the uncorrected clearance reading that was acquired from the probe. The x-axis is the actual clearance distance between the simulated fan casing, with sensor, and the tip of the blade. The calibration was done over a range of 1.0 to $13.0 \mathrm{~mm}$. The resulting curve is a second-order polynomial and has a relatively constant sensitivity over the entire range. For this calibration the sensor's polarity was aligned perpendicular to the chord of the blade. A similar shaped curve, with slightly different values, was observed for the calibration where the probe's polarity was aligned parallel to the thick blade's tip. The curve reported in Figure 6 was a typical response when using the probes against a blade whose thickness was of the same order of magnitude or greater than the diameter of the probe.

As a means of evaluating the overall accuracy and repeatability associated with the calibrations on the thick blade, both the probe and blade were reset and the experiments were repeated across the entire range with the clearance corrections applied to the measurements. The worst case error that was observed between the actual distance and the corrected distance measured by the sensor in these verification tests was $\sim 0.17 \mathrm{~mm}$. It is believed that a portion of this error can be attributed to inaccuracies and biases associated with the initial calibration setup. In subsequent calibrations on a turbofan blade for the 


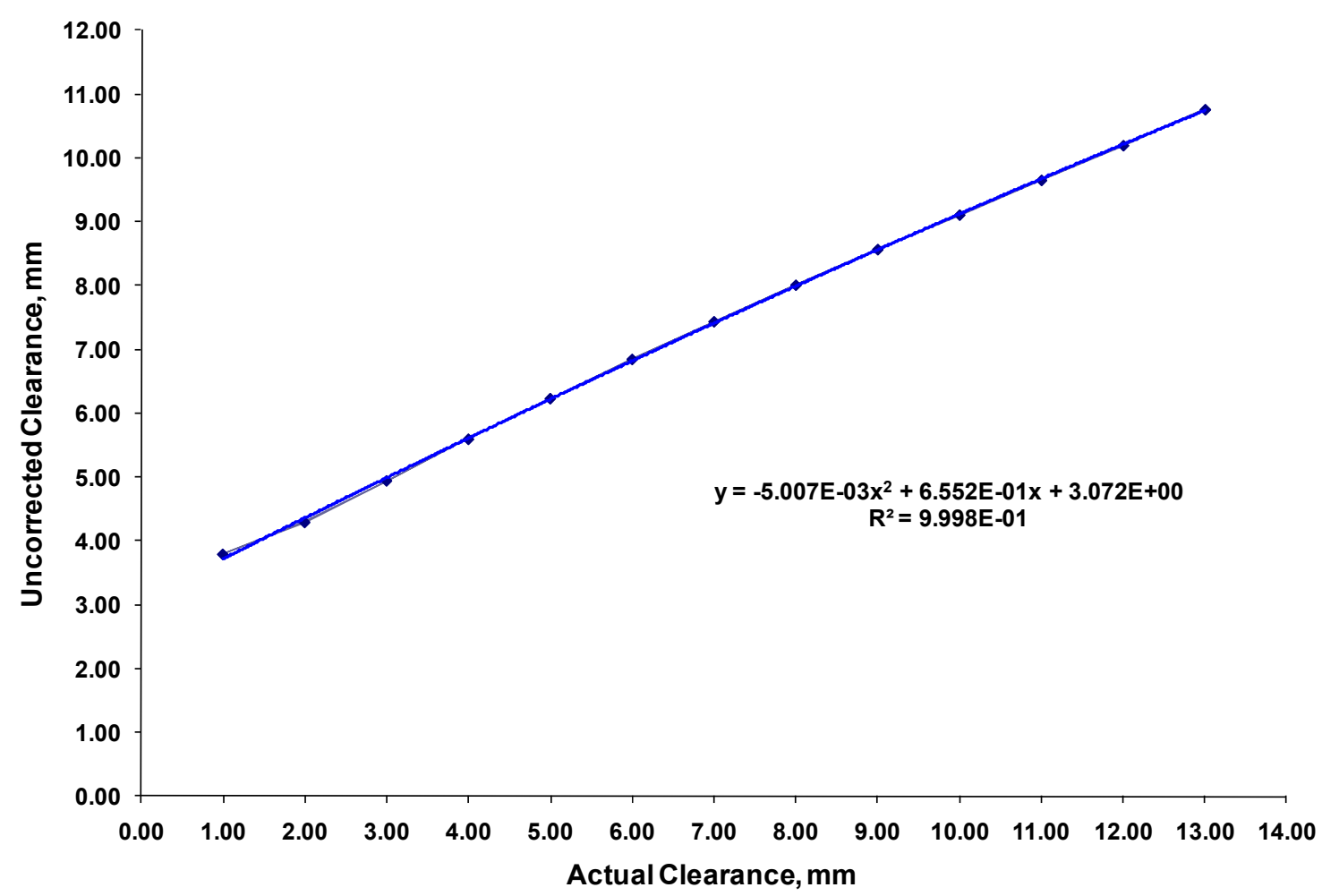

Figure 6.-Calibration curve for simulated thick blade.

NASA Turbofan experiment, improvements in the calibration setup resulted in errors that were much smaller and on the order of $\sim 0.05 \mathrm{~mm}$. In summary, these initial calibration experiments on the two different blade geometries were primarily conducted as a means to evaluate the microwave probes measurement capabilities and to develop the calibration techniques that would be required for using the probes in subsequent experiments. This initial experiment was successful in achieving these objectives.

\section{Axial Vane Fan Experiment}

The second experiment involved the use a first generation, $5.8 \mathrm{GHz}$, sensor to make tip clearance measurements on a large axial vane fan located the NASA Glenn Research Center's 10- by 10-Foot Supersonic Wind Tunnel $(10 \times 10$ SWT) Facility. The purpose of this experiment was to acquire experience in using the sensors on an actual piece of rotating machinery. It was also intended as a means to evaluate how well the calibrations accomplished in the laboratory transferred into an actual use in the field. The axial vane fan that was used is shown in Figure 7. It is part of the $10 \times 10 \mathrm{SWT}$ s infrastructure and is located in the tunnel's Air Dryer Building (Ref. 7). It is one of eight fans that are used to heat, dry, and cool the wind tunnel's alumina beds. The fan is $\sim 1.8 \mathrm{~m}$ in diameter and has 16 blades. The blades are $\sim 362 \mathrm{~mm}$ long, with a chord length of $\sim 267 \mathrm{~mm}$ and a maximum thickness of $\sim 26 \mathrm{~mm}$ at the midchord position. Provisions were made for the installation of two probes $90^{\circ}$ apart in the fan's casing at the midchord position of the blades. A calibrated microwave tip clearance probe was installed in one of the locations.

Data was acquired over several operations of the vane fan varying the configuration and setup of the sensors. Data was taken with the probe's polarity aligned both parallel and perpendicular to the blade chord in order to assess the effect of the sensor's alignment on the measurement. In addition, data was taken in the synchronous, asynchronous, corrected, and uncorrected data modes as a means to better understand the system's settings and sensor capabilities. Only a summary of the results of the test runs for this experiment is included in this paper. 


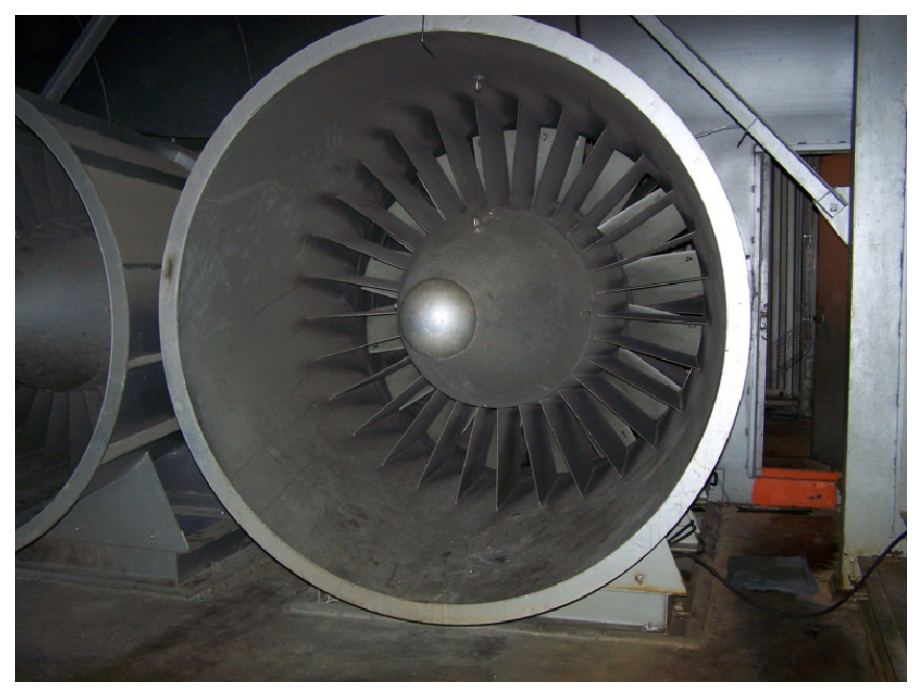

Figure 7.-Axial vane fan located at the $10 \times 10$ SWT.

The average and minimum clearances acquired during one of the test runs was analyzed. The data was acquired at a fixed sampling rate of $400 \mathrm{kHz}$ over an 8-min period of the fan operating at a steady state condition of $1200 \mathrm{rpm}$. The average blade tip clearance for the 16 blades over this time period was $2.84 \mathrm{~mm}$. The minimum clearance detected over this period was $2.17 \mathrm{~mm}$ with average minimum running at $2.55 \mathrm{~mm}$. These measurements were consistent with the expected operation of the vane fan and are in line with the clearance measurements that were made statically. For comparison, the measurements that were made statically at this probe's location yielded a 16-blade average tip clearance of $3.33 \mathrm{~mm}$ and a minimum blade tip clearance of $2.87 \mathrm{~mm}$. The approximate half a millimeter difference between the static and running clearance measurements was due to blades locking in their seats during fan operation. This effect is hard to duplicate when making static measurements. For this test case the probe was configured with its polarity perpendicular to the blade chord. Other test runs were accomplished by varying the probe's polarity (parallel to the blade chord) and acquiring data using different acquisition modes (fixed sample rate vs. synchronous sample rate). The results of these runs were similar in magnitude to the results described above. However, it was observed that for the fan's "thick" blades, a cleaner, less noisy signal was obtained with the probes polarity aligned perpendicular to the blade chord.

In regards to the sensors' ability to detect individual blade clearances, Figure 8 shows the individual clearances that were measured for one revolution of the fan. The $\mathrm{x}$-axis displays the blade number and the $\mathrm{y}$-axis displays the measured tip clearances in millimeters. For this particular revolution the measured clearances ranged from 2.34 to $3.37 \mathrm{~mm}$, with the variation in clearances between blades being on the order of tenths of millimeters. As previously indicated these clearances are in-line with the expected operation of the vane fan.

This experiment represented the first time that the microwave tip clearance probes were used at the NASA Glenn Research Center to acquire tip clearance data on actual rotating machinery. While this experiment was more of a qualitative study, its baseline objectives were successfully accomplished. Experience was gained on using the microwave probes and the system was successful in acquiring tip clearance data on the axial van fan. What was learned in this experiment was applied to future experiments. In addition, the calibrations that were accomplished in the laboratory on the simulated geometry transferred well into the field. One limitation of the experiment was that a reference sensor was not installed and used to compare the readings acquired from the microwave sensors. This weakness was acknowledged and there are future plans to install the microwave sensors in the axial vane fan or another test rig along with another type of clearance sensor (capacitive, eddy current, etc.) as a means of acquiring comparison data. 


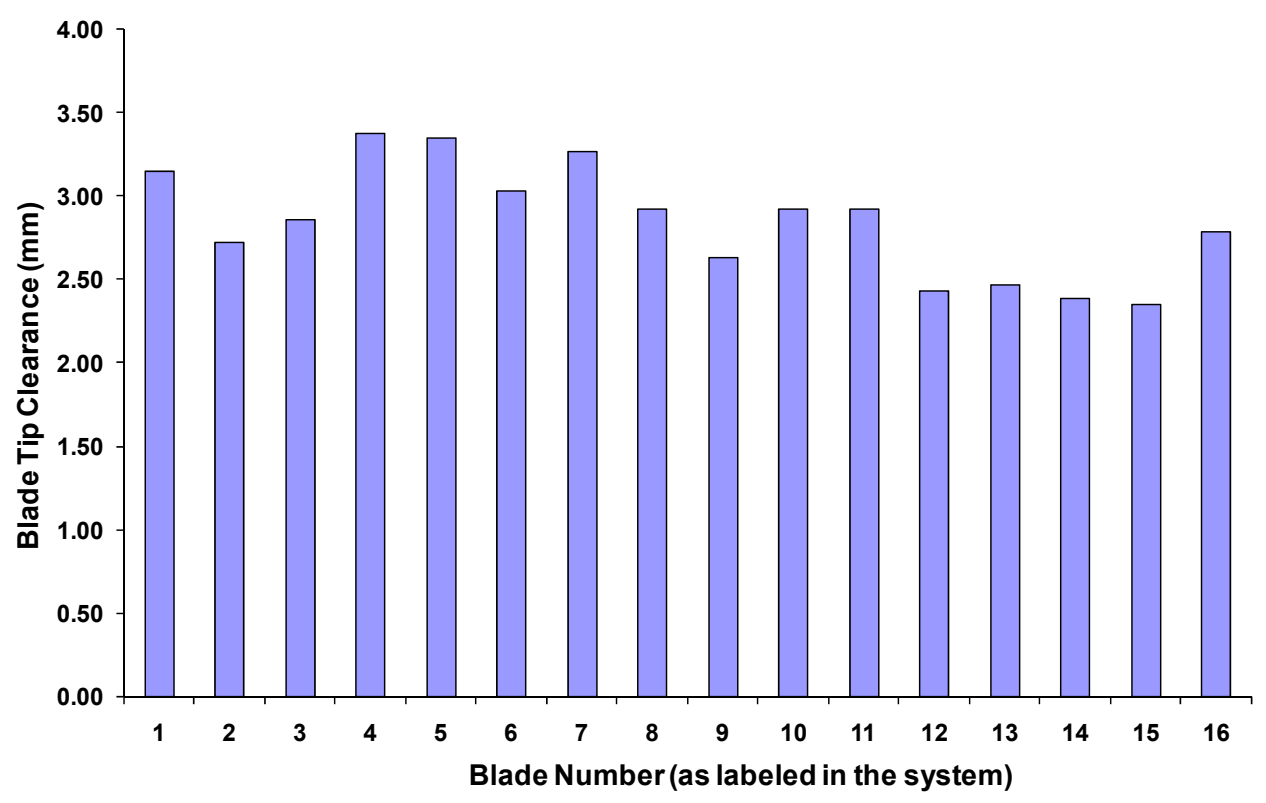

Figure 8.--Individual blade tip clearances on axial vane fan for one revolution.

\section{NASA Turbofan Experiment}

The third experiment used two first generation, $5.8 \mathrm{GHz}$, microwave sensors to obtain tip clearance data on a NASA turbofan test article that was tested in the Glenn Research Center's 9- by 15-Foot LowSpeed Wind Tunnel $(9 \times 15$ LSWT) Facility (Ref. 8). The purpose of this experiment was to evaluate the sensor's ability to acquire data on aero engine size test article and blades. The turbofan has 18 blades and is shown in Figure 9. It is being used to develop and evaluate noise reduction concepts under NASA's Subsonic Fixed Wing Program. Two probes were installed $90^{\circ}$ apart in the turbofan's casing at the midchord position of the blades. The first probe was installed at the $90^{\circ}$ position, which is on the lefthand side of the casing looking downstream at the fan. The second probe was installed at the $180^{\circ}$ position, which is on the bottom of the casing looking downstream at the fan.

This application was a little different than the Axial Vane Fan Experiment presented in the previous section of this paper. First, the blades were made out of a non-ferrous composite material. The tips of these blades were nickel coated to allow measurement by the microwave sensors. Second, the turbofan's casing was lined with a non-ferrous abradable material so the fan blades would not be damaged in the event of a blade rub during operation. However, for the sensors to work properly they needed to be installed in a metallic casing to allow the microwave field to properly propagate from it. To accomplish this, the sensors were recessed in the non-ferrous rub strip at a distance greater than normally done, in order to use the metallic part of the casing as the required reference plane. This also had the benefit of moving the sensors back to a much safer location in the event that a deep blade rub was experienced. For this experiment, holes were drilled all the way through the casing including the non-ferrous liner in order to facilitate the probe installation and the collection of physical distance measurements. However, since the sensors have the ability to see through a non-ferrous material, a better idea would have been to only drill far enough to let the probes be installed in the metallic part of the liner and to leave the non-ferrous rub strip intact. This would have resulted in a clean and intact flow path, allowing clearance measurements to be made during all phases of the test program. It is planned to pursue this type of installation for the next test entry of the NASA Turbofan. 


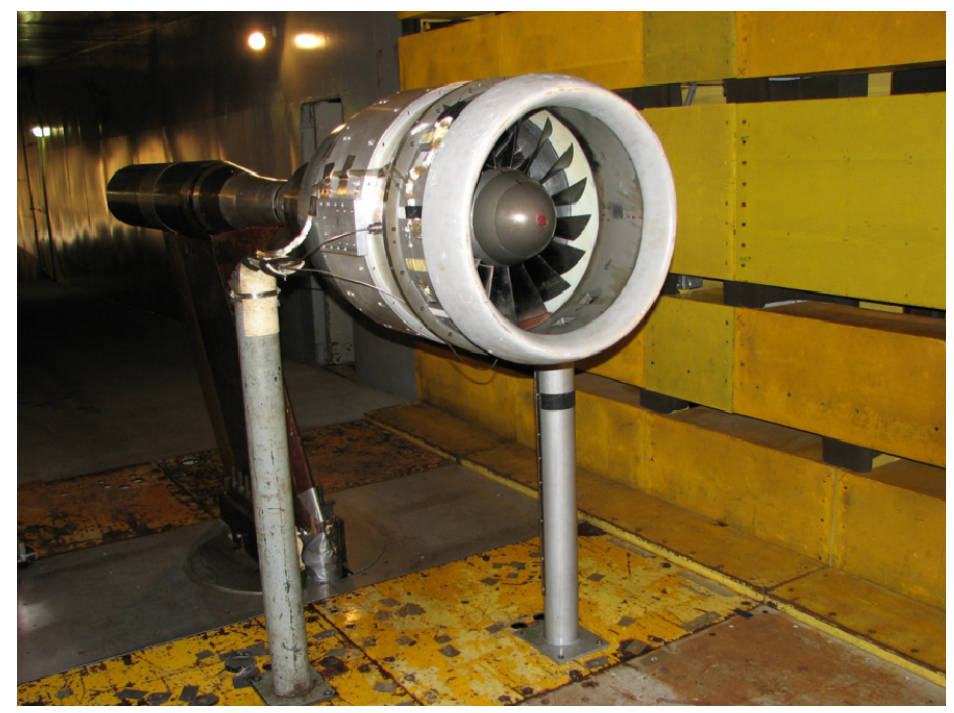

Figure 9.-NASA Turbofan.

In order to make the tip clearance measurements on the turbofan a series of calibrations were carried out to map the actual clearance to the uncorrected clearance measured by the sensor. The calibration was performed using the previously described calibration rig with a turbofan blade mounted on the rotary table and the probes installed in an actual section of the fan casing. This setup allowed the calibration to be done in a configuration that was as close as possible to the actual use on the turbofan. It also allowed the offset due to the probe being recessed in the non-ferrous rub strip to be included in the calibration. For this application the sensor's polarity was aligned to be parallel with the chord of the blade tip to maximize the amount of energy reflected from the blade. The calibrations were accomplished over a range from 1.0 to $3.0 \mathrm{~mm}$ between the tip of the blade and the fan casing. As a means of evaluating the calibration and its repeatability, a verification test was conducted by resetting the probe and repeating the measurements across the entire range with the clearance correction curve being applied to the measurements. The largest difference that was observed between the actual clearance and the corrected clearance in this verification was $\sim 0.05 \mathrm{~mm}$. This was a major improvement when compared to the errors observed in the initial calibration experiments.

Blade tip clearance data was acquired for several test runs of the NASA turbofan. Data was acquired at a variable sampling rate that was synchronized to the fans speed. Each measurement consisted of two revolutions of data with 10,000 samples taken per revolution. Figure 10 shows the 18-blade average tip clearance measurements and the fan speed for one of the test runs. From these charts it is observed that the average tip clearance decreases as the fan speed is increased. This result is expected and is mostly due to the growth of the composite blades as the fan operates at higher speeds. Probe \#1 measured a decrease of $0.22 \mathrm{~mm}$ and probe \#2 measured a decrease of $0.06 \mathrm{~mm}$ as the speed increased to $8875 \mathrm{rpm}$. The change in clearance observed in this experiment was within the range predicted for these blades. In addition, the change in tip clearances measured by the microwave sensors were very similar to previously observed values. In a previous test entry using capacitive clearance sensors, changes in tip clearances up to $0.22 \mathrm{~mm}$ were observed when the turbofan was operated over the same speed range.

An additional means of viewing the data is shown in the polar plot of Figure 11. This plot displays the individual blade clearances measured by probe \#1 for several fan speeds. As noted earlier, this plot shows that the individual blade tip clearances decrease as the fan speed is increased. This plot further reveals that the microwave clearance probes are sensitive enough and have sufficient resolution to pick up the minor variations that exist in the individual blade tip clearances. 


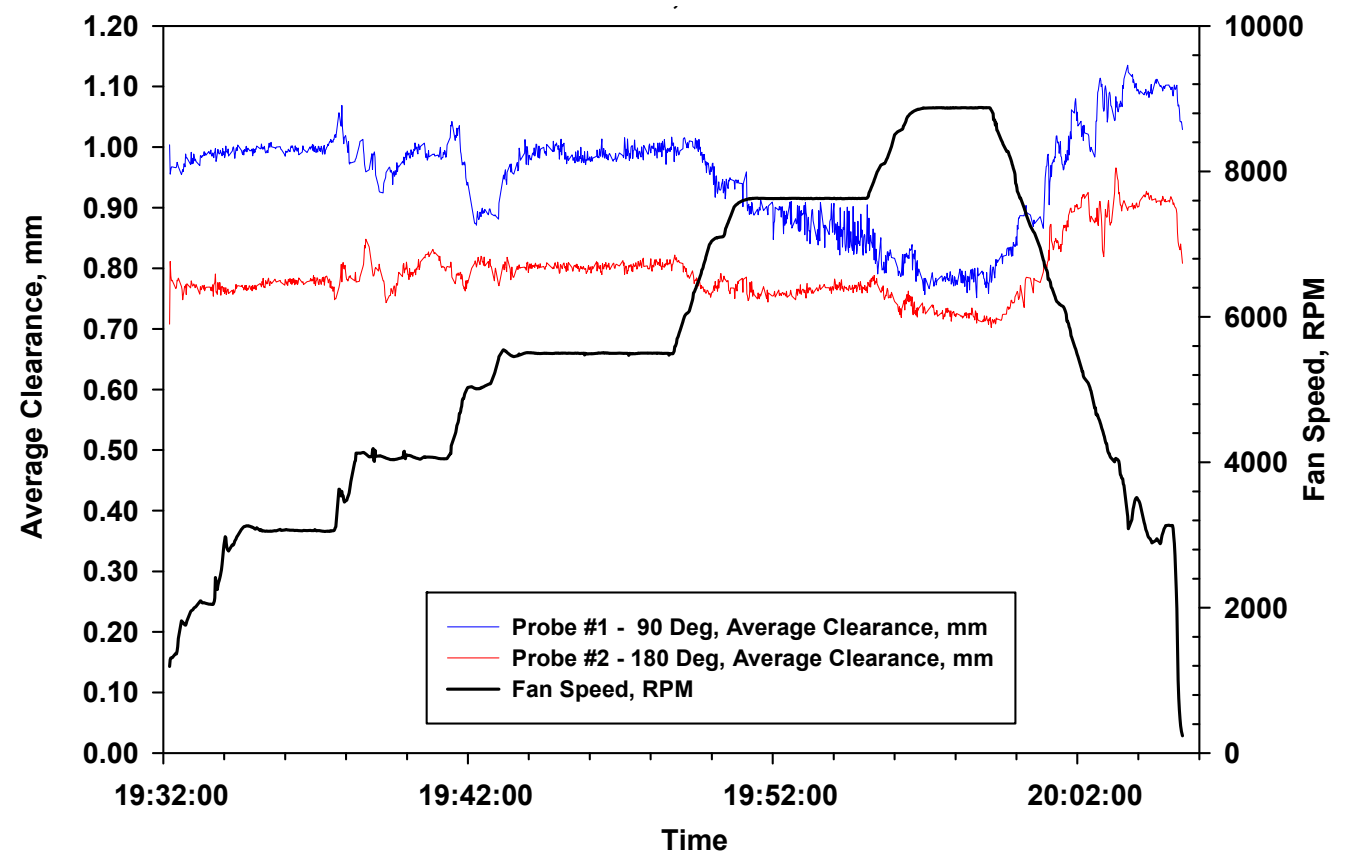

Figure 10.-Average blade tip clearances and fan speed from NASA Turbofan experiment.

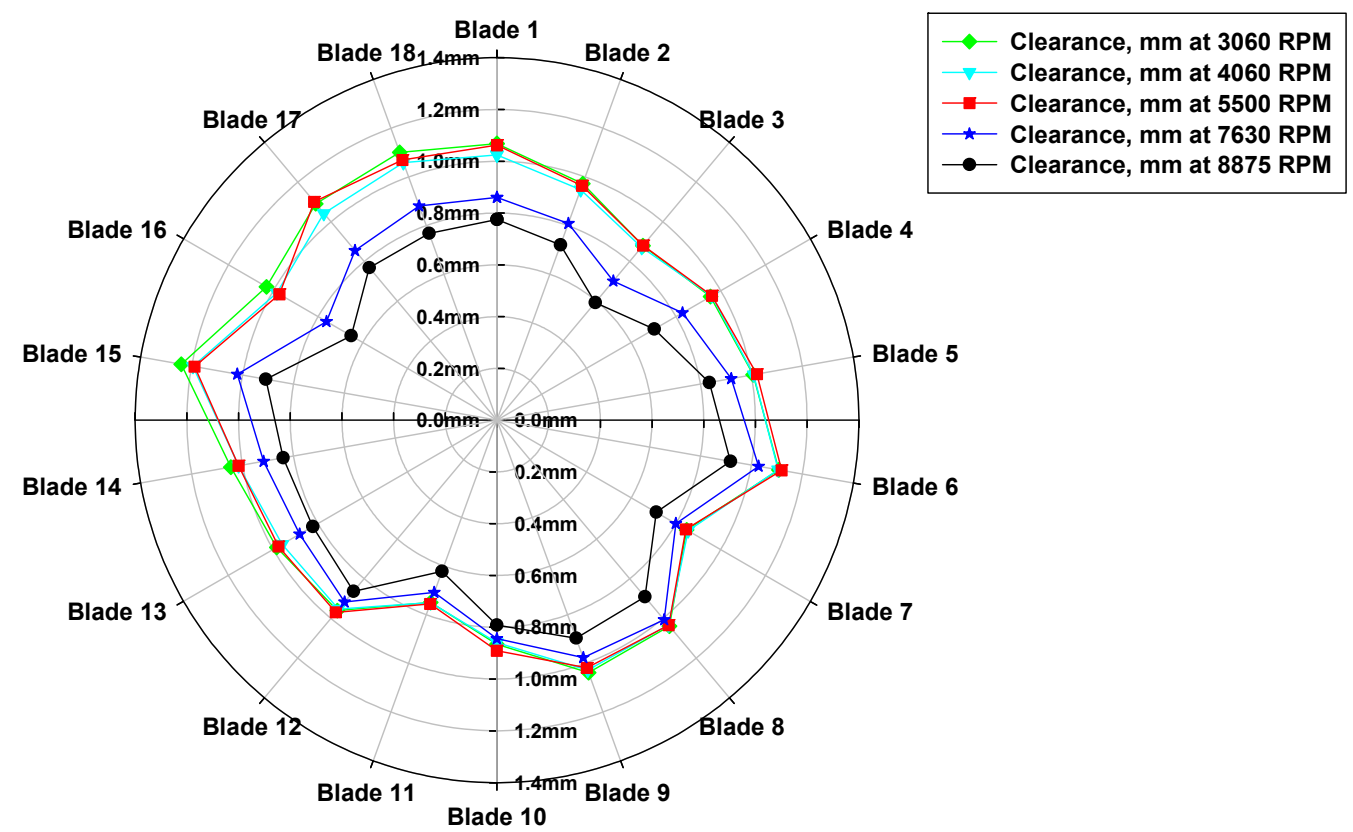

Figure 11.-Individual blade tip clearances for probe \#1, $90^{\circ}$ location—NASA Turbofan experiment. 
One anomaly that was observed in the data of Figure 10 is the difference in the absolute clearance values measured by each of the probes. The average blade tip clearance measurement made at static conditions for probes \#1 and \#2 was 0.86 and $0.91 \mathrm{~mm}$, respectively. Assuming that the blades do not experience much growth at low speed, the clearances measured at these speeds should be close to the values measured statically. Using this assumption, it is observed in Figure 13 that probe \#1 was reading $\sim 0.14 \mathrm{~mm}$ high and probe \#2 was reading $\sim 0.13 \mathrm{~mm}$ low in absolute clearance values. It is believed that this zero shift in measured clearances is due to dissimilarities between the probes' installation on the turbofan and the installation used for the calibration. Any differences in probe alignment and installation depth will affect the accuracy of the measurement. Improved techniques will be used in future experiments to better control these parameters so the installation used in the calibration will more closely match the installation used on the test article.

In summary, this experiment has successfully demonstrated the microwave clearance probe's ability to make measurements on aero engine size hardware. This was a conservative test of the first generation, $5.8 \mathrm{GHz}$ microwave sensors in that the blade size and clearances that were measured were more suited for the use of the second generation, $24 \mathrm{GHz}$ sensors. The blade tip clearances measured by the first generation probes were consistent with results previously observed for this turbofan. The experiment also showed that the probes can be used to make measurements on applications that are not typical for their designed use. The sensors were able to make measurements on blades made of composite materials by coating the blade tips with nickel. In addition, the sensor's ability to see through the non-ferrous portion of the rub strip allowed it to be recessed further in the fan's casing than would have normally been done. This has a positive ramification for future experiments where it will be attempted to keep the non-ferrous portion of the rub strip intact allowing these sensors to make tip clearance measurements on this fan over its entire range of testing without affecting the fan's acoustic or aero performance. It is also planned to make improvements to the calibration and installation processes so the installation used in the calibration more closely matches the actual use on an engine or test article.

\section{Blade Tip Deflection Experiment}

The fourth experiment involved the use of the second generation, $24 \mathrm{GHz}$, probe on a subscale simulated engine disk for the primary purpose of investigating the microwave sensors ability to make blade tip deflection measurements. The subscale engine disk is shown in Figure 12. The Aluminum disk has an outside diameter of $254 \mathrm{~mm}$ and a uniform thickness of $19 \mathrm{~mm}$. It has 32 blades that are $3.175 \mathrm{~mm}$ thick and $19 \mathrm{~mm}$ long. Six of the blades were bent at pre-defined angles as shown in Figure 12. This disk and a second generation $24 \mathrm{GHz}$ sensor were mounted on the microwave sensor calibration rig that was previously described in Section IV. The calibration rig provided an ideal venue for this experiment in that it allowed for precise control of the clearances to be measured. For this experiment the simulated engine disk was operated at speeds up to $200 \mathrm{rpm}$ both blade tip clearance and blade tip deflection data were acquired over a range of clearances for several test runs.

The goal of this experiment was two-fold. The primary objective was to see how effective the probes were in measuring blade tip deflection. Large deflection values were initially chosen for this proof of concept test with the rationale that it was better to start with larger deflections that could be readily detected, with the intent of eventually working towards detecting smaller values in order to find a lower measurement limit. For this initial deflection measurement experiment a 32 blade disk with 6 blades prebent at angles of $\pm 2^{\circ}, \pm 4^{\circ}, \pm 8^{\circ}$ was used. The secondary objective was to evaluate the microwave sensors ability to make clearance measurements at extremely low ranges. The NASA IVHM Project metric for this sensor technology is to be able to make clearance measurements to absolute values of $0.10 \mathrm{~mm}$. This experiment provided an ideal environment where clearances could be controlled down to this level using the linear positioning stage of the calibration rig. The set-up also allowed the demonstration of being able to get both clearance and deflection measurements from one sensor, which is a desired capability for IVHM propulsion health monitoring applications. 


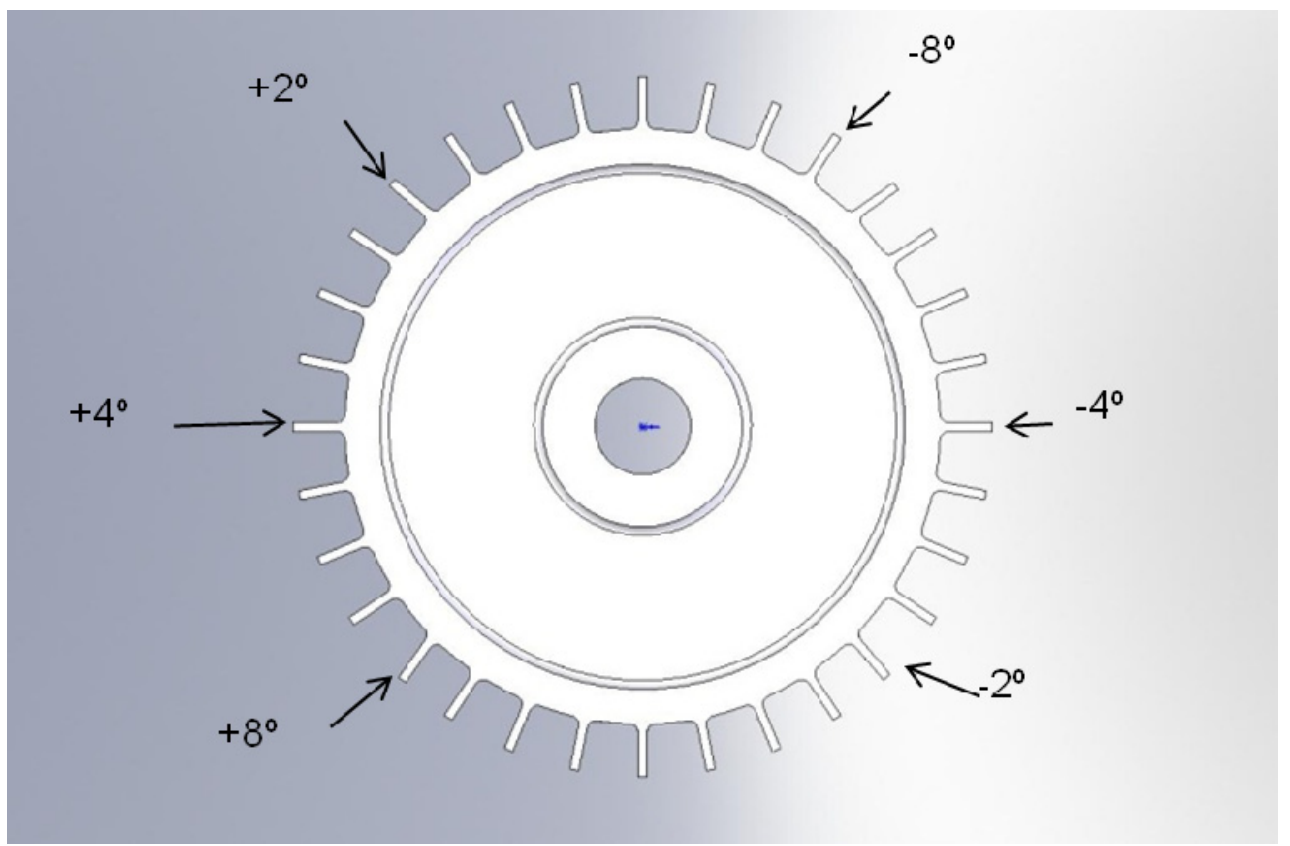

Figure 12.-Simulated turbine disk with pre-bent blades for blade tip deflection testing.

For this experiment, a total of two test series were conducted on the disk, each using a different $24 \mathrm{GHz}$ sensor. Each test series consisted of a calibration test, which was used to calibrate the microwave sensors against the disk's blade geometry. After the calibration was completed the calibration curves were applied to the system and an additional two to three verification tests were conducted for each sensor to collect blade tip clearance and blade tip deflection data and assess the individual sensors' performance. In this experiment the microwave sensors' polarity was aligned to be parallel with the chord of the blade tip to maximize the amount of energy reflected from the blade, which is consistent with their use on thin blades.

The calibration curves for the two sensors that were used in this experiment are shown in Figures 13 and 14. As in previous calibration examples discussed earlier, the y-axis is the uncorrected clearance reading that was acquired from the probe. The $\mathrm{x}$-axis is the actual clearance measured by the linear stage's encoder and verified with precision gage blocks or feeler gages. The first sensor was calibrated over a range from 0.10 to $0.60 \mathrm{~mm}$. The second sensor was calibrated over a slightly larger range from 0.05 to $0.70 \mathrm{~mm}$. The resulting calibration curves were third-order polynomials. As previously described, after the microwave sensors were calibrated, the corrections were applied to the system and verification tests were conducted on the sensors to assess their accuracy. A maximum clearance measurement error of $0.033 \mathrm{~mm}$ was observed during the two verification tests conducted for the first sensor. A maximum clearance measurement error of $0.025 \mathrm{~mm}$ was observed during the three verification tests conducted for the second sensor. It was sensed by the authors that the clearance measurements acquired during this experiment were of good quality and met the goal of being able to achieve clearance measurements as low as $0.10 \mathrm{~mm}$ with accuracies close to the desired goal of $\pm 0.025 \mathrm{~mm}$.

Figures 15 and 16 show the results of the blade tip deflection measurements for the respective sensors from one of the verification tests. The deflection measurements were made at a nominal tip clearance of $0.10 \mathrm{~mm}$. The $\mathrm{x}$-axis on the two graphs indicates the blade number of the disk. The y-axis on the graphs is the blade tip deflection that was measured by the microwave sensors. The actual blade tip deflections, measured by physical inspection of the disk, are also superimposed on these graphs. From the data presented in the graphs, it can be seen that the microwave sensors were able to detect and measure the deflections of the pre-bent blades. In addition, based on the observed noise floor, the sensor appeared to have sufficient sensitivity to detect deflections well under the $2^{\circ}(\sim 0.70 \mathrm{~mm})$ deflection that the disk had as it smallest deflection angle. 


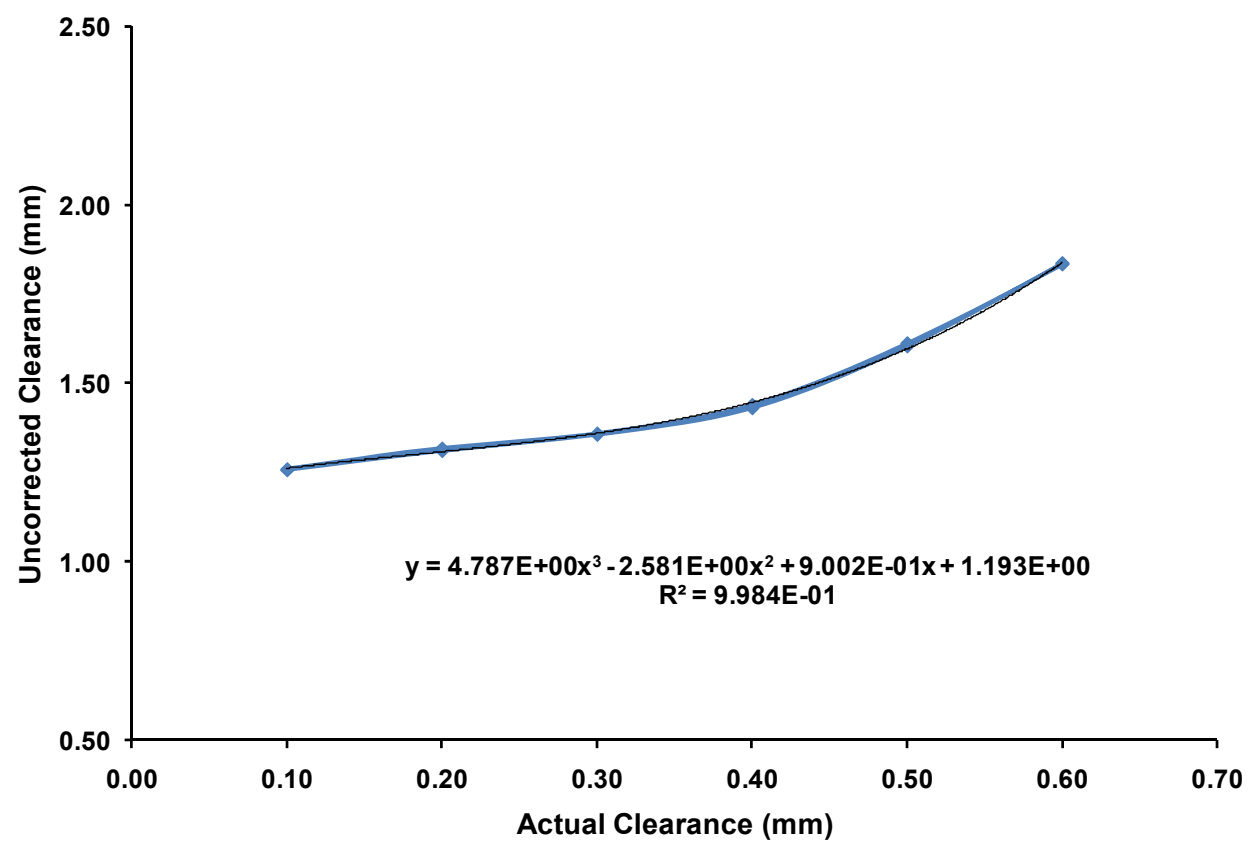

Figure 13.-Calibration curve for sensor \#1, SN007-Blade tip deflection experiment.

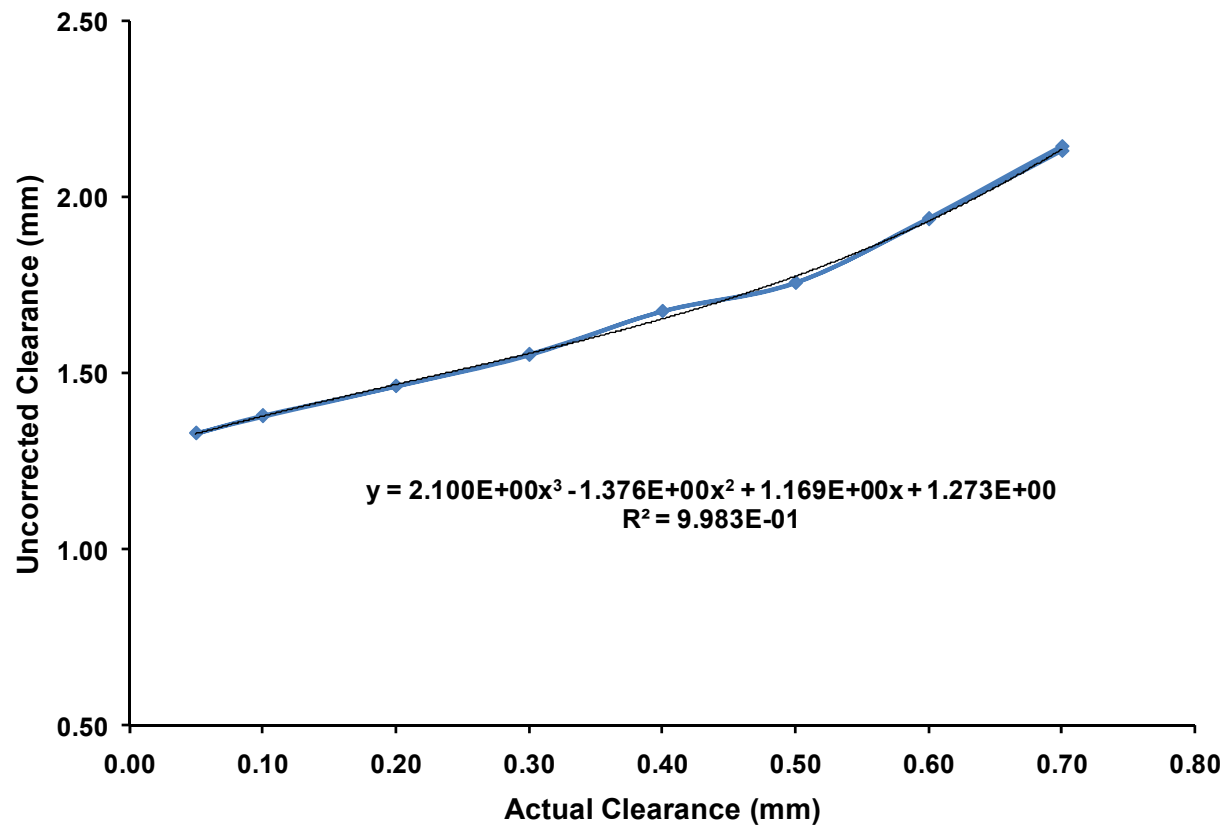

Figure 14.-Calibration curve for sensor \#2, SN002-Blade tip deflection experiment. 


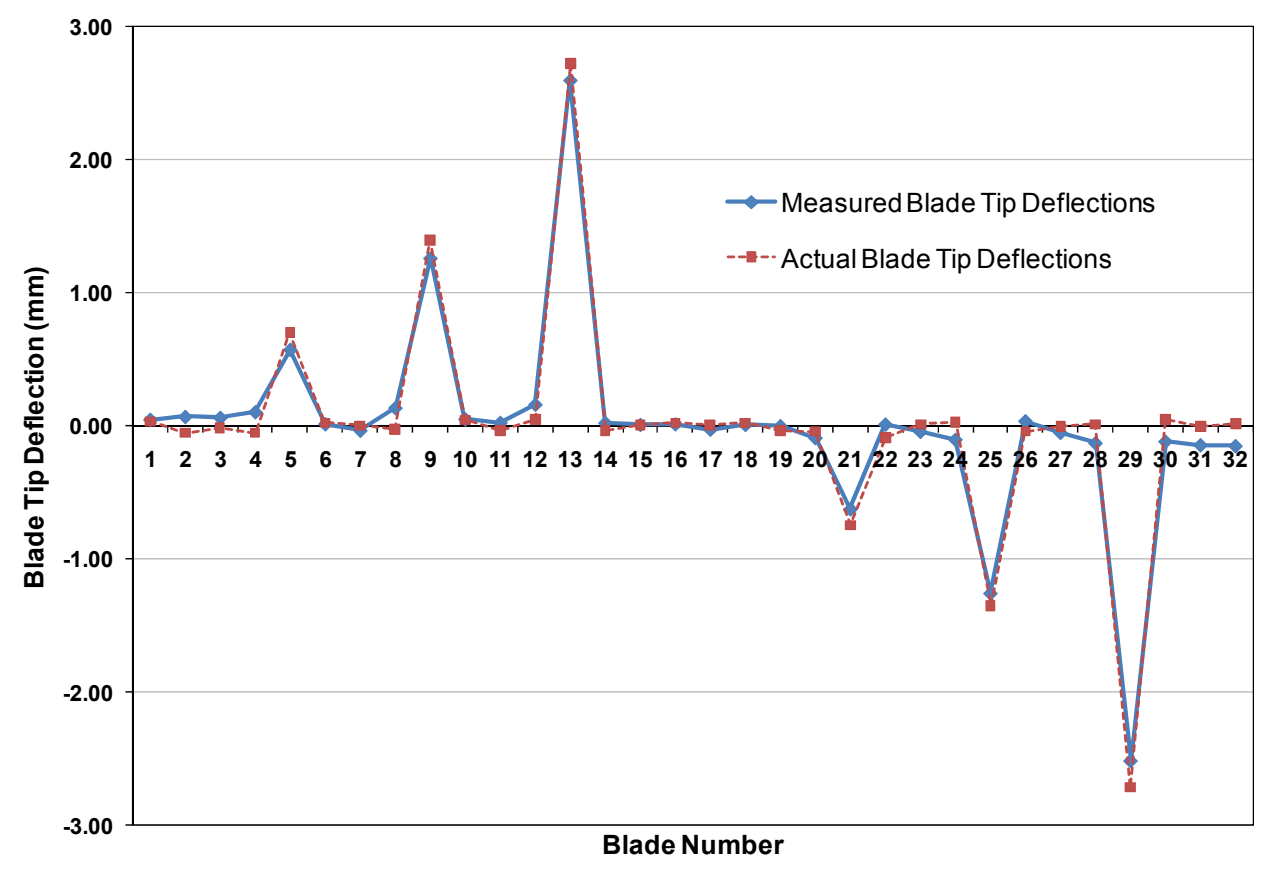

Figure 15.-Blade tip deflection measurements, sensor \#1, SN007 at $0.10 \mathrm{~mm}$ clearance.

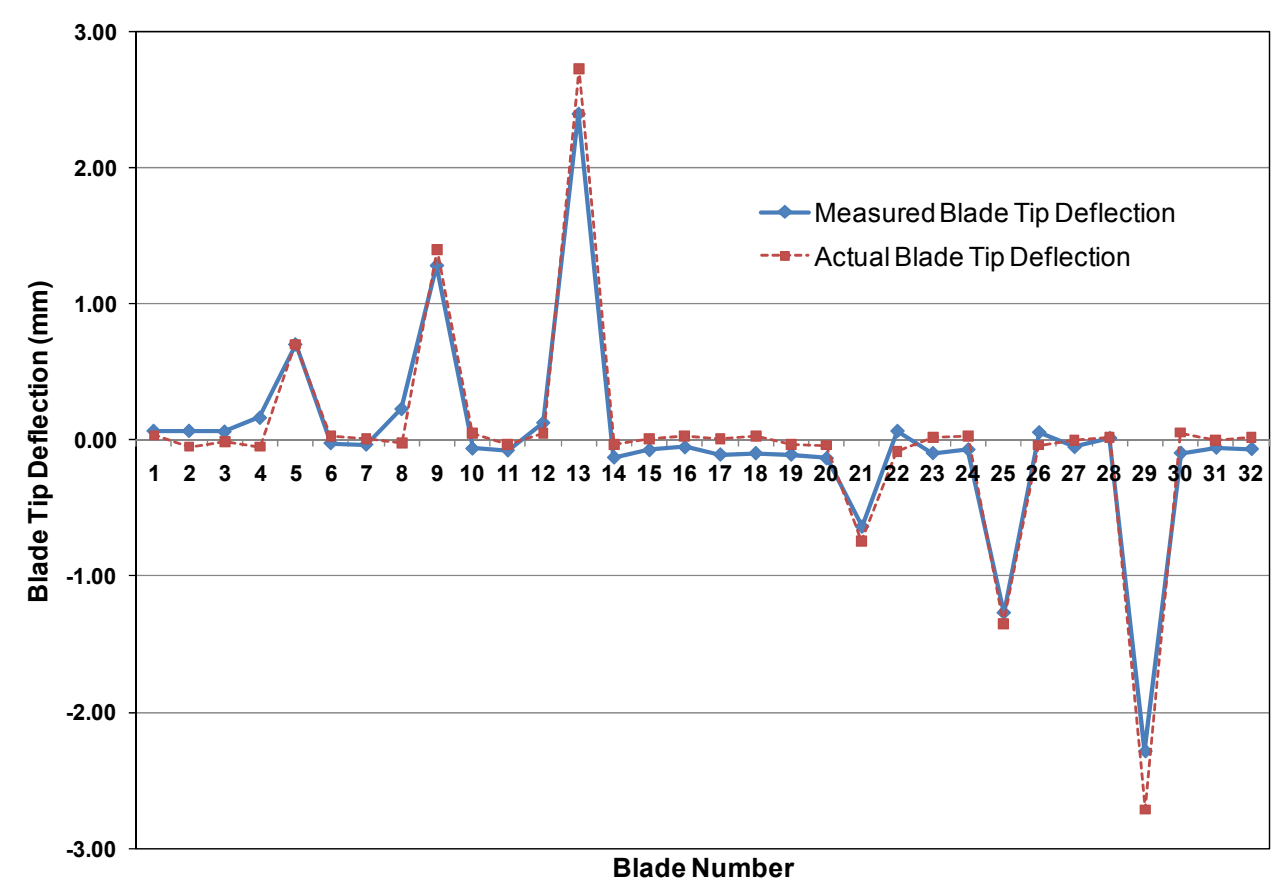

Figure 16.-Blade tip deflection measurements, sensor \#2, SN002 at $0.10 \mathrm{~mm}$ clearance. 
Table 1 shows the errors in deflection measurements for the first sensor. For the first sensor the blade deflection measurement errors ranged from $\sim 0.10$ to $\sim 0.20 \mathrm{~mm}$ over the $2^{\circ}$ to $8^{\circ}$ deflection range. The additional verification test for this sensor yielded similar results. Table 2 shows the errors in deflection measurement for the second sensor. For this sensor the errors ranged from $\sim 0.00$ to $\sim 0.42 \mathrm{~mm}$ over the blade deflection range. Again, the two additional verification tests for this sensor yielded similar results. The error on the measurements at the $2^{\circ}$ and $4^{\circ}$ deflections are on the order of $\pm 0.10 \mathrm{~mm}$ for both sensors and seem reasonable for this proof-of-concept experiment. The error at the $8^{\circ}$ deflection is much larger, with $\sim 0.20 \mathrm{~mm}$ for sensor \#1, and $\sim 0.42 \mathrm{~mm}$ for sensor \#2.

TABLE I.-BLADE TIP DEFLECTION MEASUREMENTS FOR SENSOR \#1, SN007

\begin{tabular}{|cccc|}
\hline $\begin{array}{c}\text { Nominal blade } \\
\text { Deflection }(\mathrm{Deg})\end{array}$ & $\begin{array}{c}\text { Actual deflection }(\mathrm{mm}) \\
\text { From Physical inspection }\end{array}$ & $\begin{array}{c}\text { Measured deflection }(\mathrm{mm}) \\
\text { From sensor }\end{array}$ & Error $(\mathrm{mm})$ \\
\hline+2 & 0.70 & 0.58 & -0.12 \\
+4 & 1.40 & 1.26 & -0.14 \\
+8 & 2.73 & 2.60 & -0.13 \\
-2 & -0.74 & -0.62 & 0.12 \\
-4 & -1.35 & -1.25 & 0.10 \\
-8 & -2.71 & -2.51 & 0.20 \\
\hline
\end{tabular}

TABLE II.-BLADE TIP DEFLECTION MEASUREMENTS FOR SENSOR \#2, SN002

\begin{tabular}{|cccc|}
\hline $\begin{array}{c}\text { Nominal blade } \\
\text { Deflection (Deg) }\end{array}$ & $\begin{array}{c}\text { Actual deflection }(\mathrm{mm}) \\
\text { From Physical inspection }\end{array}$ & $\begin{array}{c}\text { Measured deflection }(\mathrm{mm}) \\
\text { From sensor }\end{array}$ & Error (mm) \\
\hline+2 & 0.70 & 0.70 & 0.00 \\
+4 & 1.40 & 1.28 & -0.12 \\
+8 & 2.73 & 2.40 & -0.33 \\
-2 & -0.74 & -0.64 & 0.10 \\
-4 & -1.35 & -1.27 & 0.08 \\
-8 & -2.71 & -2.29 & 0.42 \\
\hline
\end{tabular}

It is theorized that this error at the higher deflection angles is due to an artifact of the simplified processing method that was used for this initial proof of concept type experiment. The current algorithm that was used for computing the measured blade tip deflection is based on how the measured blade-toblade distance varies from the nominal distance. The trigger point for this simplified algorithm is the point where the minimal clearance is measured, as opposed to using a repeatable geometrical location such as blade leading or trailing edge. This leads to errors especially at the larger deflection angles where the minimum clearance point is not necessarily the same point used for the geometrical measurement. However, it has to be recognized that this was just an initial test to investigate if the probes could be used to make deflection measurements. Artificially large deflection angles were used with the intent of further refining the process. It was felt by the authors that this initial proof-of-concept testing was successful and the probes show potential to measure deflection. Future plans are to continue the testing and to work with the manufacturer in refining the blade tip deflection measurement capabilities.

\section{Compressor Disk Calibration Experiment}

The fifth experiment involved the calibration of a second generation, $24 \mathrm{GHz}$, probe using an actual compressor disk from a small aero engine for the purpose of investigating the sensors ability to make blade tip clearance measurements on realistic aero engine hardware. These measurements were made in a laboratory environment by mounting the compressor disk and the sensor on the microwave sensor calibration rig, using the same set-up that was used for the blade tip deflection and calibration experiments. As in the preceding experiment, the calibration rig provided an ideal venue in that it allowed 


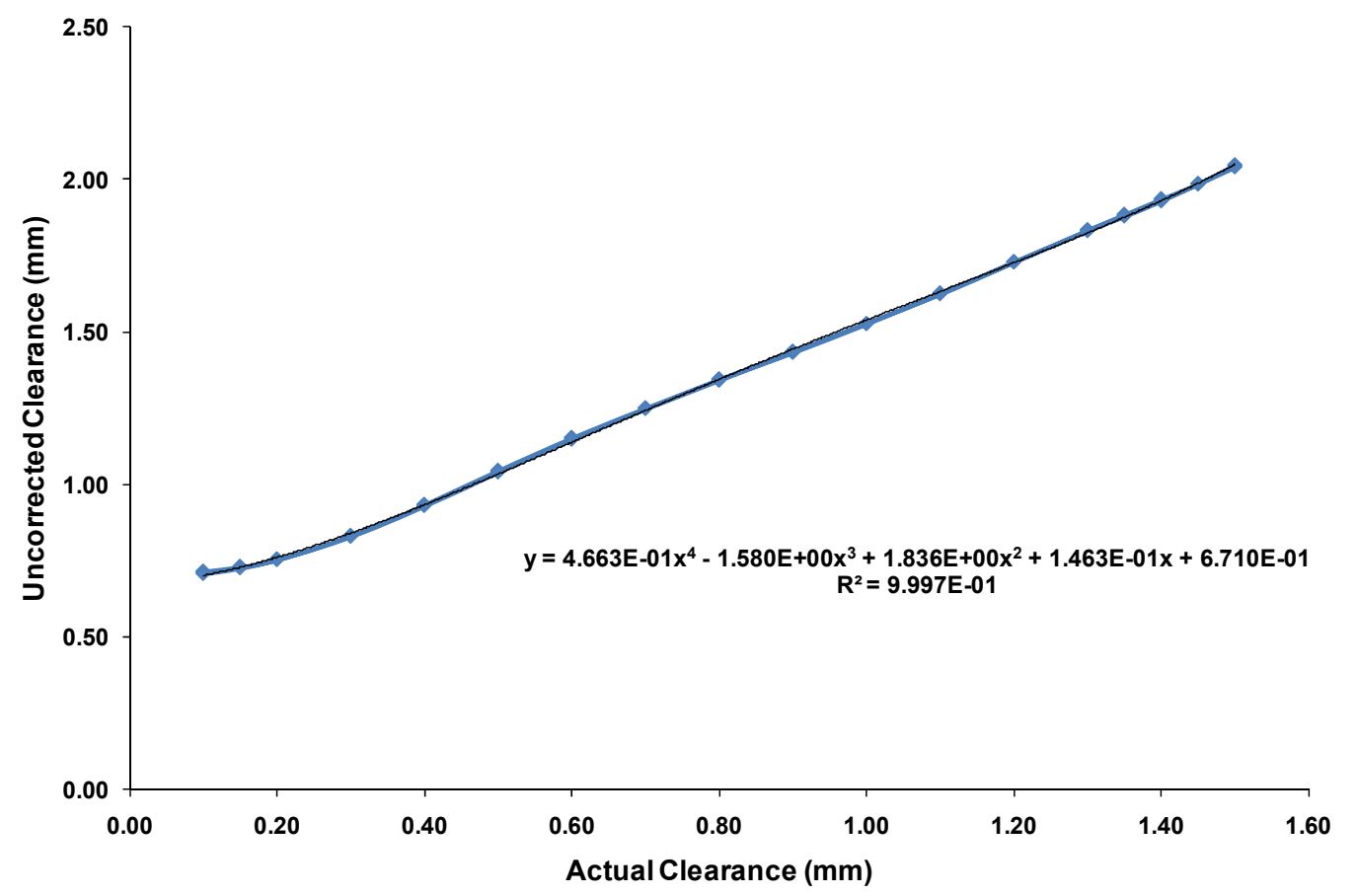

Figure 17.-Calibration curve for sensor SN002-Compressor disk experiment.

for precise control of the clearances to be measured. For this experiment the compressor disk was operated at speeds up to $200 \mathrm{rpm}$ and the blade tip clearances were varied over a range of 0.10 to $1.50 \mathrm{~mm}$. The probe's polarity was aligned to be $45^{\circ}$ with respect to the blade tip's chord to mimic a potential set-up on an actual engine.

For this experiment a total of four tests were conducted on one sensor. The first test was used for the initial sensor calibration. The three subsequent tests were to verify the calibration and assess the sensor's accuracy. The curve for the calibration is shown in Figure 17. The calibration was completed over a range from 0.10 to $1.50 \mathrm{~mm}$. The $y$-axis is the uncorrected clearance reading that was acquired from the probe. The $\mathrm{x}$-axis is the actual clearance measured by the linear stage's encoder and verified with precision gage blocks or feeler gages. The resulting curve was a fourth-order polynomial. As earlier stated, after the calibration the correction curve was applied to the system and three additional tests were conducted over the same range to assess the probes accuracy. During the three verification tests a maximum error of $0.021 \mathrm{~mm}$ was observed. These results were encouraging in that the sensor was able to make measurements on aero engine hardware over a relatively low clearance range within the desired accuracy of $\pm 0.025 \mathrm{~mm}$. However, it is acknowledged that these results were achieved in the ideal set-up of a laboratory and that the results may differ in an actual engine, due to noise and other environmental effects.

\section{Conclusions and Future Work}

The experimentation that has been accomplished to date has shown that the microwave blade tip clearance sensor technology is a viable option for propulsion health monitoring applications. The sensors have been successfully demonstrated on rotating machinery and other aero engine hardware. The first generation, $5.8 \mathrm{GHz}$, sensors were used on a large Axial Vane Fan and a NASA Turbofan to acquire blade tip clearance data. The second generation, $24 \mathrm{GHz}$, sensors were used to make basic blade tip deflection and low range clearance measurements on a simulated engine disk that had pre-bent blades. The second generation sensors were also calibrated and used on a small compressor disk on a calibration 
spin rig. Over the next year it is planned to test the sensors in several spin and rotating machinery test rigs at NASA GRC as a means of further evaluating their performance in a more relevant engine environment. It is also planned to continue the blade tip deflection experiments in order to refine the sensor's deflection measurement capability. A ground test with these sensors installed on a full scale engine is planned for the 2011 time frame.

\section{References}

1. U.S. Department of Transportation, Federal Aviation Administration, "Engine Damage-Related Propulsion System Malfunctions," DOT/FAA/AR-08/24, 2008.

2. Holst, T.A., Kurfess, T.R., Billington, S.A., Geisheimer, J.L., and Littles, J.L, "Development of an Optical-Electromagnetic Model of a Microwave Blade Tip Sensor," AIAA-2005-4377, 2005.

3. Geisheimer, J.L., Billington, S.A, Holst, T., and Burgess, D.W., "Performance Testing of a Microwave Tip Clearance Sensor," AIAA-2005-3987, 2005.

4. Geisheimer, J.L., Billington, S.A, and Burgess, D.W., "A Microwave Blade Tip Clearance Sensor for Active Clearance Control Applications," AIAA-2004-3720, 2004.

5. Holst, T.A., "Analysis of Spatial Filtering in Phase-Based Microwave Measurements of Turbine Blade Tips," Master's Thesis, Georgia Institute of Technology, Atlanta, Georgia, August 2005.

6. Woike, M., Roeder, J., Hughes, C., and Bencic, T., "Testing of a Microwave Blade Tip Clearance Sensor at the NASA Glenn Research Center," NASA/TM-2009-215589, AIAA-2009-1452, 2009.

7. Soeder, R.H., Roeder, J.W., Linne, A.L., and Panek, J.W., "User Manual for NASA Glenn 10- by 10Foot Supersonic Wind Tunnel," NASA/TM-2004-212697, 2004.

8. Soeder, R.H., "NASA Lewis 9- by 15-Foot Low-Speed Wind Tunnel User Manual," NASA TM$106247,1993$. 


\begin{tabular}{|c|c|c|c|c|c|}
\hline \multicolumn{5}{|c|}{ REPORT DOCUMENTATION PAGE } & $\begin{array}{c}\text { Form Approved } \\
\text { OMB No. 0704-0188 }\end{array}$ \\
\hline \multicolumn{6}{|c|}{$\begin{array}{l}\text { The public reporting burden for this collection of information is estimated to average } 1 \text { hour per response, including the time for reviewing instructions, searching existing data sources, gathering and maintaining the } \\
\text { data needed, and completeting and reviewing the collection of information. Send comments regarding this burden estimate or any other aspect of this collection of information, including suggestions for reducing this } \\
\text { burden, to Department of Defense, Washington Headquarters Services, Directorate for Information Operations and Reports (0704-0188), } 1215 \text { Jefferson Davis Highway, Suite } 1204 \text {, Arlington, VA } 22202-4302 \text {. } \\
\text { Respondents should be aware that notwithstanding any other provision of law, no person shall be subject to any penalty for failing to comply with a collection of information if it does not display a currently valid OMB } \\
\text { control number. } \\
\text { PLEASE DO NOT RETURN YOUR FORM TO THE ABOVE ADDRESS. }\end{array}$} \\
\hline \multicolumn{2}{|c|}{$\begin{array}{l}\text { 1. REPORT DATE (DD-MM-YYYY) } \\
01-06-2010\end{array}$} & \multicolumn{3}{|c|}{$\begin{array}{l}\text { 2. REPORT TYPE } \\
\text { Technical Memorandum }\end{array}$} & 3. DATES COVERED (From - To) \\
\hline \multirow{3}{*}{\multicolumn{5}{|c|}{$\begin{array}{l}\text { 4. TITLE AND SUBTITLE } \\
\text { A Microwave Blade Tip Clearance Sensor for Propulsion Health Monitoring }\end{array}$}} & 5a. CONTRACT NUMBER \\
\hline & & & & & 5b. GRANT NUMBER \\
\hline & & & & & 5c. PROGRAM ELEMENT NUMBER \\
\hline \multirow{3}{*}{\multicolumn{5}{|c|}{$\begin{array}{l}\text { 6. AUTHOR(S) } \\
\text { Woike, Mark, R.; Abdul-Aziz, Ali; Bencic, Timothy, J. }\end{array}$}} & 5d. PROJECT NUMBER \\
\hline & & & & & 5e. TASK NUMBER \\
\hline & & & & & $\begin{array}{l}\text { 5f. WORK UNIT NUMBER } \\
\text { WBS 645846.02.07.03.11.03 }\end{array}$ \\
\hline \multicolumn{5}{|c|}{$\begin{array}{l}\text { 7. PERFORMING ORGANIZATION NAME(S) AND ADDRESS(ES) } \\
\text { National Aeronautics and Space Administration } \\
\text { John H. Glenn Research Center at Lewis Field } \\
\text { Cleveland, Ohio 44135-3191 }\end{array}$} & $\begin{array}{l}\text { 8. PERFORMING ORGANIZATION } \\
\text { REPORT NUMBER } \\
\text { E-17313 }\end{array}$ \\
\hline \multirow{2}{*}{\multicolumn{5}{|c|}{$\begin{array}{l}\text { 9. SPONSORING/MONITORING AGENCY NAME(S) AND ADDRESS(ES) } \\
\text { National Aeronautics and Space Administration } \\
\text { Washington, DC 20546-0001 }\end{array}$}} & $\begin{array}{l}\text { 10. SPONSORING/MONITOR'S } \\
\text { ACRONYM(S) } \\
\text { NASA }\end{array}$ \\
\hline & & & & & $\begin{array}{l}\text { 11. SPONSORING/MONITORING } \\
\text { REPORT NUMBER } \\
\text { NASA/TM-2010-216736 }\end{array}$ \\
\hline \multicolumn{6}{|c|}{$\begin{array}{l}\text { 12. DISTRIBUTION/AVAILABILITY STATEMENT } \\
\text { Unclassified-Unlimited } \\
\text { Subject Categories: } 33,35 \text {, and } 07 \\
\text { Available electronically at http://gltrs.grc.nasa.gov } \\
\text { This publication is available from the NASA Center for AeroSpace Information, 443-757-5802 }\end{array}$} \\
\hline \multicolumn{6}{|c|}{ 13. SUPPLEMENTARY NOTES } \\
\hline \multicolumn{6}{|c|}{$\begin{array}{l}\text { 14. ABSTRACT } \\
\text { Microwave sensor technology is being investigated by the NASA Glenn Research Center as a means of making non-contact structural health } \\
\text { measurements in the hot sections of gas turbine engines. This type of sensor technology is beneficial in that it is accurate, it has the ability to } \\
\text { operate at extremely high temperatures, and is unaffected by contaminants that are present in turbine engines. It is specifically being targeted } \\
\text { for use in the High Pressure Turbine (HPT) and High Pressure Compressor (HPC) sections to monitor the structural health of the rotating } \\
\text { components. It is intended to use blade tip clearance to monitor blade growth and wear and blade tip timing to monitor blade vibration and } \\
\text { deflection. The use of microwave sensors for this application is an emerging concept. Techniques on their use and calibration needed to be } \\
\text { developed. As a means of better understanding the issues associated with the microwave sensors, a series of experiments have been } \\
\text { conducted to evaluate their performance for aero engine applications. This paper presents the results of these experiments. }\end{array}$} \\
\hline \multicolumn{6}{|c|}{$\begin{array}{l}\text { 15. SUBJECT TERMS } \\
\text { Gas turbine engines; IVHM; Blade tip clearance; Aeropropulsion }\end{array}$} \\
\hline \multicolumn{3}{|c|}{ 16. SECURITY CLASSIFICATION OF: } & $\begin{array}{l}\text { 17. LIMITATION OF } \\
\text { ABSTRACT }\end{array}$ & $\begin{array}{l}\text { 18. NUMBER } \\
\text { OF }\end{array}$ & $\begin{array}{l}\text { 19a. NAME OF RESPONSIBLE PERSON } \\
\text { STI Help Desk (email:help } @ \text { sti.nasa.gov) }\end{array}$ \\
\hline $\begin{array}{l}\text { a. REPORT } \\
\text { U }\end{array}$ & $\begin{array}{l}\text { b. ABSTRACT } \\
\text { U }\end{array}$ & $\begin{array}{l}\text { C. THIS } \\
\text { PAGE } \\
\text { U }\end{array}$ & UU & $\begin{array}{l}\text { PAGES } \\
24\end{array}$ & $\begin{array}{l}\text { 19b. TELEPHONE NUMBER (include area code) } \\
443-757-5802\end{array}$ \\
\hline
\end{tabular}



